\title{
IGFBPs modulate IGF-I- and high glucose-controlled growth of human retinal endothelial cells
}

\author{
S Giannini, B Cresci, L Pala, A Ciucci ${ }^{1}$, A Franchini ${ }^{2}$, \\ C Manuelli ${ }^{3}$, Y Fujita-Yamaguchi ${ }^{4}$, P Cappugi ${ }^{3}$, R Zonefrati ${ }^{5}$ \\ and C M Rotella
}

Department of Clinical Pathophysiology, Endocrinology Unit, Diabetes and Metabolic Diseases Section, University of Florence, viale Pieraccini 6,
50134 Florence, Italy
${ }^{1}$ Institute of Endocrine Sciences, IRCCS, University of Milan, 20100 Milan, Italy
${ }^{2}$ Ophthalmology Clinic, University of Florence, Florence, Italy
${ }^{3}$ Institute of Dermatology and Venereology, University of Florence, Florence, Italy
${ }^{4}$ Department of Molecular Genetics, Beckman Research Institute of the City of Hope, Duarte, California 91010, USA
${ }^{5}$ Department of Internal Medicine, University of Florence, Florence, Italy
(Requests for offprints should be addressed to C M Rotella; Email: c.rotella@ dfc.unifi.it)

\begin{abstract}
Insulin-like growth factor binding proteins (IGFBPs) are important local factors in the development of proliferative diabetic retinopathy. We investigated the effects of IGF-I and increased glucose concentrations on the release of IGFBPs and the growth of human retinal endothelial cells (HRECs). HRECs secrete IGFBPs-2 to -5. IGF-I stimulated thymidine incorporation and modified the pattern of IGFBPs, decreasing the inhibitory IGFBP-4 through down-regulation of its mRNA, and increasing IGFBP-5 which, per se, was able to modulate HREC growth, exerting post-transcriptional control. Studies using an antibody ( $\alpha$ IR 3 ) against the IGF-I receptor, and compounds with low affinity for IGFBPs, such as insulin and des(1-3)IGF-I, showed that an interaction between IGF-I and IGFBP-5 was necessary to detach this IGFBP from
\end{abstract}

its binding sites. The dose of IGF-I that significantly decreased the IGFBP-4/IGFBP-5 ratio was the same that stimulated HREC growth. Chronic exposure to high concentrations of glucose was able to reduce HREC mitogenesis, interacting with the IGF system through a decrease in the stimulatory IGFBPs-2, -3 and -5 , leaving the concentration of the inhibitory IGFBP-4 constant. These results extend our previous observations in endothelial cells and suggest that the IGFBP-4/IGFBP-5 ratio regulates IGF-I-induced growth of HRECs, whereas a general decrease in IGFBPs (except for IGFBP-4) was the anti-proliferative effect of chronic exposure to high glucose concentrations.

Journal of Endocrinology (2001) 171, 273-284

\section{Introduction}

Diabetes mellitus is associated with microvascular complications that include thickening of the basement membrane and endothelial cell dysfunction (Rudermann et al. 1992). The diabetic proliferative retinopathy is characterised by the formation of new and aberrant vasculature on the surface of the retina, suggesting that angiogenic factors may be involved. Many reports focused the attention on growth hormone $(\mathrm{GH})$, insulin-like growth factor-I (IGF-I), fibroblast growth factor (FGF), transforming growth factor- $\beta$ (TGF- $\beta$ ), platelet-derived growth factor (PDGF) and vascular endothelial growth factor (VEGF) (Paques et al. 1997). However, an editorial by Merimee (1997) shed light on the important role of the IGF system (IGFs-I and -II and their carrier proteins, the IGF binding proteins (IGFBPs)) in the pathogenetic mechanism of this diabetic complication.

IGFs are well-known growth promoters found in the blood in association with IGFBPs that modulate their activity. These IGFBPs may either inhibit or potentiate the bioavailability of IGF through several mechanisms (Jones \& Clemmons 1995). To date, six classically distinct IGFBPs have been well characterised (Shimasaki \& Ling 1991), and the new concept of an IGF superfamily has emerged with the identification of some low-affinity IGF binding proteins, the IGFBP-related proteins (IGFBPsrP1 to -rP4) (Kim et al. 1997). With regard to the IGF system, in vivo studies show conflicting results: IGF-I concentrations in the vitreous of diabetic patients 
correlated positively with its serum concentrations (Grant et al. 1986), whereas a weak increase in serum IGF-I was observed in patients with proliferative diabetic retinopathy (Bach \& Rechler 1992), suggesting that locally high concentrations of IGF-I may be more important than systemic concentrations. In addition, IGFBPs were increased in the vitreous of neovascularised diabetic eyes (Meyer Schwickerath et al. 1993). In vitro studies, indeed, have shown the IGF system to have a role in retinal endothelial cell proliferation. IGF-I has been demonstrated to be a potent angiogenic factor in rabbit retina (Grant et al. 1993b) and in bovine retinal endothelial cells (King et al. 1985), even through modulation of the IGFBPs (Giannini et al. 1997). The only report concerning the effect of IGF-I on human retinal endothelial cells (HRECs) (Grant et al. 1993a) confirmed this growth factor as promoting endothelial cell growth. As different types of endothelial cells, including HRECs, have been demonstrated to produce IGFBPs (Bar et al. 1989, Moser et al. 1992, Yang et al. 1993, Giannini et al. 1997, 1999, Spoerni et al. 1998, Tucci et al. 1998), the purpose of this study was to investigate the role that these IGFBPs could have in the modulation of IGF-I bioavailability, extending our previous observations on different endothelial cell IGFBPs (Giannini et al. 1997, 1999).

The major metabolic abnormality in diabetes is hyperglycaemia, and high glucose concentrations result, in vitro, in delayed proliferation of microvascular human endothelial cells (Lorenzi et al. 1987). As glucose-compromised retinal endothelial cell renewal could be the first lesion, leading to acellular capillaries and then presenting an angiogenic stimulus to uncontrolled endothelial cell replication (Lorenzi \& Cagliero 1991), we also investigated whether and how the increased ambient glucose concentrations could interfere with the early stages of IGF/IGFBP-controlled growth of HRECs.

\section{Materials and Methods}

\section{Cell isolation, culture and characterisation}

HRECs were obtained post-mortem from two pairs of eyes from donor patients (men aged 58 and 52 years). Two independent isolations were made and the isolates were subsequently pooled, giving a single cell line. Retinal endothelial cells were isolated essentially according to a procedure published previously ( $\mathrm{Su} \&$ Gillies 1992). Briefly, the retinas were aseptically dissected from the eyes and teased and cut into small pieces that were centrifuged three times at $1000 \mathrm{~g}$ for $2 \mathrm{~min}$ (4235 centrifuge, PBI International, Milan, Italy). They were then incubated at $37^{\circ} \mathrm{C}$ for $3 \mathrm{~h}$ in $50 \mathrm{ml}$ sterile solution containing $1 \mathrm{mg} / \mathrm{ml}$ collagenase type II (Worthington Biochemical Corporation, New Jersey, NJ, USA). The solution was washed and centrifuged at $1000 \mathrm{~g}$ for $5 \mathrm{~min}$. The pellet obtained was finally resuspended in regular culture medium consisting of Coon's modified Ham F12 medium containing 10\% Nu Serum IV (Collaborative Research, Bedford, MA, USA), 1\% Ultroser G (IBF Biotechnics, Savage, MD, USA), $100 \mathrm{U} / \mathrm{ml}$ penicillin and $100 \mu \mathrm{g} / \mathrm{ml}$ streptomycin, and plated onto gelatin-coated plates (Corning Co., Corning, NY, USA). Cellular outgrowth from cultured microvessels consisted of colonies of HREC and pericytes; however, a low-serum cell culture medium was used to select endothelial cells in further passages. When confluent, HRECs were dispersed with trypsin and transferred onto $100 \mathrm{~cm}^{2}$ culture plates (Corning Co.).

Cells were identified as endothelial using morphological and biochemical markers as previously reported (Giannini et al. 1999). In particular, we characterised HRECs as endothelial cells by the binding of antibodies to factor VIII-correlated antigen and by indirect immunofluorescence for CD31, a platelet endocytosed adhesion molecule. The immunohistochemical method was based on using a rabbit anti-human antibody for the two specific endothelial markers. HRECs maintained endothelial markers and secretion of IGFBPs constantly from passage 1 to passage 10 , with a positive pattern of $95 \%$ even if we utilised the cells for our experiments between the 3rd and the 5 th passages. However, for experiments on basal characterisation of IGFBPs only (northern blots and immunoblots), HRECs were utilised between the 5 th and 10th passages. During the prolonged cell proliferation (3 weeks), HRECs were grown under the following experimental conditions: (1) normal glucose culture medium (5 mM); (2) high-glucose culture medium (25 mM); (3) $14 \mathrm{mM}$ mannitol+11 $\mathrm{mM}$ glucose culture medium to match the osmolarity of the high-glucose medium.

\section{Collection of conditioned medium, identification and immunocharacterisation of IGFBPS}

Cells were seeded in $25 \mathrm{~cm}^{2}$ tissue culture flasks at a density of $35 \times 10^{3}$ cells $/ \mathrm{cm}^{2}$ in regular medium. Twenty-four hours later, cells were washed with PBS and cultured in $1.5 \mathrm{ml}$ serum-free culture medium for $48 \mathrm{~h}$ (basal conditions) or in serum-free culture medium for $24 \mathrm{~h}$ and then in serum-free culture medium containing des(1-3)IGF-I (Peninsula, Belmont, CA, USA), $\alpha$ IR3 (a kind gift from Dr M Maggi,University of Florence, Italy) and growth factors (Sigma Chemical Co., St Louis, MO, USA) at different concentrations for $24 \mathrm{~h}$. Conditioned medium was then collected and stored at $-80{ }^{\circ} \mathrm{C}$ in polypropylene tubes (Nalgene, Nalge Company/Sybron Co., Rochester, NY, USA), already treated as described previously (Giannini et al. 1994) to reduce non-specific binding of proteins to tubes. After the collection of conditioned medium, cell numbers were determined and the volume of conditioned medium for analysis adjusted accordingly.

IGFBPs in the conditioned medium were examined by western blotting, carried out according to the method of 
Hossenlop et al. (1986). Briefly, $100 \mu \mathrm{l}$ conditioned medium, together with pre-stained molecular weight marker proteins (Bio-Rad, Richmond, CA, USA) underwent SDS-PAGE $(12 \%$ gel; $18 \times 12 \mathrm{~cm})$ in non-reducing conditions. Proteins separated on the gel were then transferred onto a nitrocellulose membrane at $10 \mathrm{~V}$ for $16 \mathrm{~h}$, using a transblotting cell apparatus (Bio-Rad). The nitrocellulose membrane (Sartorius AG, Gottingen, Germany) was prewashed with buffers containing detergents and incubated for $2 \mathrm{~h}$ at room temperature with $1 \times 10^{6}$ c.p.m. $\left[{ }^{125} \mathrm{I}\right] \mathrm{IGF}-\mathrm{II}$ (Amersham, Milan, Italy). The membrane was then washed, dried and autoradiographed after 3 days exposure of the film (Eastman Kodak, Rochester, NY, USA) at $-80^{\circ} \mathrm{C}$. Protein band intensity in western blot was analysed by scanning densitometry of the original autoradiographic film with a Flowvision densitometer (Lynx, San Mateo, CA, USA). To quantify the intensity of radioactivity of various IGFBPs, several autoradiographs developed after different times of exposure of the same blot were measured, and data within a linear range were used.

For immunoblotting, conditioned medium was subjected to SDS-PAGE under non-reducing conditions and then electrophoretically transferred onto a nitrocellulose membrane as described above for western ligand blotting. Polyclonal antibodies against IGFBPs-2, to -6 were purchased from UBI (UBI, Lake Placid, NY, USA) and goat antibody immunoglobulin $G$ conjugated with alkaline phosphatase was obtained from Sigma Immuno Chemicals; a rabbit anti-human antibody labelled with horseradish peroxidase was from American Quialex, La Mirada, CA, USA. The nitrocellulose membranes were incubated at $4{ }^{\circ} \mathrm{C}$ with a $1: 300$ diluted AbBPs- 2 and -5 , 1:1000 diluted AbBPs-3 and -4, in PBS containing 3\% non-fat dry milk. The nitrocellulose membranes were rinsed three times with PBS-3\% milk and incubated at $25^{\circ} \mathrm{C}$ for $3 \mathrm{~h}$ in PBS-3\% milk with an anti-rabbit immunoglobulin G-alkaline phosphatase conjugate for IGFBPs-2 and -3 , or with a rabbit anti-human antibody labelled with horseradish peroxidase for IGFBPs-4 and -5 . The membrane was then washed once with $0 \cdot 1 \mathrm{~mol} / 1$ Tris chloride buffer $\mathrm{pH} 9.5$ containing $0.1 \mathrm{~mol} / 1 \mathrm{NaCl}$ and $5 \mathrm{mmol} / \mathrm{l} \mathrm{MgCl}_{2}$, and then incubated with the detection systems according to the manufacturer's instructions: bromochloroindole phosphate-nitroblue tetrazolium substrate solution for IGFBPs-2 and -3 and an enhanced chemiluminescence detection system (ECL, Amersham, Arlington, IL, USA) for IGFBPs-4 and -5 .

\section{RNA preparation and Northern blot analysis}

Total RNA was prepared from HRECs cultured in regular medium with different concentrations of glucose (in the 3-week cell proliferation experiment) or IGF-I, using the guanidium thiocyanate-phenol-chloroform extraction method (Chomczynsky \& Sacchi. 1987). A $20 \mu \mathrm{g}$ lane of total RNA was loaded onto $1 \%$ agarose formaldehyde gel and run at $80 \mathrm{~V}$ for $3.5 \mathrm{~h}$ in 3morpholinopropanesulphonic acid. The gel was then stained with ethidium bromide to check that the ribosomal RNAs were intact and equal amounts of RNA had been loaded. The gel was incubated with $50 \mathrm{mM} \mathrm{NaOH}$, $10 \mathrm{mM} \mathrm{NaCl}$ for $10 \mathrm{~min}$ and neutralised with $1 \mathrm{M}$ ammonium acetate and blotted onto GeneScreen (Du Pont-NEN, Boston, MA, USA). The gels were then hybridised with complementary DNA (cDNA) probes for IGFBPs-1 to -6 , obtained from plasmid human IGFBPs (a kind gift of Dr Shunichi Shimazaki, JCR Biopharmaceuticals Inc., San Diego, CA, USA) and human $\beta$-actin cDNA (kind gift from Dr C Mavilia). All the probes were labelled using the Prime-H random primer kit (Stratagene, La Jolla, CA, USA). Each blot was hybridised with $2 \times 10^{6}$ c.p.m. $/ \mathrm{ml}$ probe in $50 \%$ formamide, $3.6 \times$ SSPE solution $(0.5 \mathrm{M} \mathrm{NaCl}, 5 \mathrm{mM}$ EDTA and $50 \mathrm{mM}$ sodium phosphate $\mathrm{pH} 6 \cdot 8$ ), 1\% SDS, $10 \%$ dextran sulphate, $5 \times$ Denhart's solution) at $42{ }^{\circ} \mathrm{C}$ overnight. The blot was finally washed in $2 \times$ SSPE, $0 \cdot 2 \%$ SDS at room temperature, followed by $0 \cdot 1 \times \mathrm{SSPE}-0 \cdot 2 \% \mathrm{SDS}$ at $60{ }^{\circ} \mathrm{C}$, and finally autoradiographed.

\section{$\left.P^{3} H\right]$ Thymidine incorporation}

Thymidine incorporation was carried out on HRECs using a procedure described previously (Rotella et al. 1989). Briefly, HRECs were plated in six multiwells in regular medium and allowed to adhere for 12-18 h. They were then maintained for $24 \mathrm{~h}$ in serum-free medium and stimuli or vehicles were added at the various indicated concentrations. All the stimuli used were purchased from Sigma Chemical Co., whereas recombinant human (rh) IGFBP-5 was purchased from Immunological and Biochemical Testsystem (Germany). In order to study the effect of different glucose concentrations on HRECs, some experiments were performed using two subpopulations of cells that had been grown in the same culture medium but adjusted for glucose concentration to either $5 \mathrm{mM}$ or $22 \mathrm{mM}$ and then evaluated after 7, 14 and 21 days of culture. Cells were pulsed with $1 \mu \mathrm{Ci} /$ well $\left[{ }^{3} \mathrm{H}\right]$ thymidine (New England Nuclear) for $4 \mathrm{~h}$ and harvested by hypotonic lysis and filtration onto glass fibre filters (Flow Lab, Costa Mesa, CA, USA). Individual filters were counted by liquid scintillation in a $\beta$-counter.

\section{Data analysis}

Results are expressed as mean values \pm standard deviation (S.D.). Statistical significance was calculated using variance analysis (ANOVA) and Dunnett's multiple comparison. Experiments were repeated at least three times, with consistent results. 


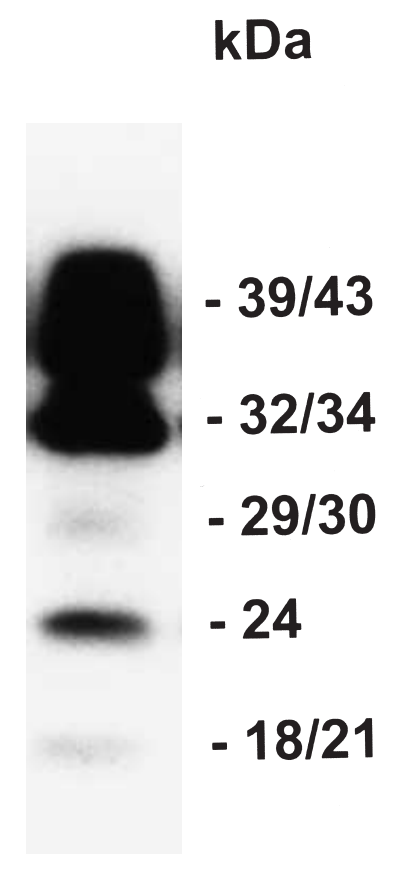

HREC

Figure 1 IGFBP profile obtained by western ligand blot of the conditioned medium from HRECs. Samples were subjected to SDS-PAGE on a $10 \%$ acrylamide gel and then probed with $\left[{ }^{125}\right.$ I]IGF-II. Molecular masses are expressed as kDa on the right of the Figure. A representative gel after a 3-day exposure is shown.

\section{Results}

Western ligand and immunoblot analysis, and $m R N A$ expression of HREC IGFBPS

IGF-II western ligand blot analysis (Fig. 1) showed that, after $48 \mathrm{~h}$ of culture, HRECs secreted into the conditioned medium several forms of IGFBPs: predominantly the 39/43, 32/34 and $24 \mathrm{kDa}$ forms. Besides these, two additional protein bands of about 29/30 and a fainter band of $18 / 21 \mathrm{kDa}$ were detectable. In order to improve the ligand blot autoradiographic bands, HREC conditioned medium was subjected to western immunoblot analysis using polyclonal antisera against human IGFBPs-1 to -6 (Fig. 2), identified with two different techniques of detection. The results obtained with the alkaline phosphatase detection system (left half of Fig. 2) revealed that the 39/43 and the 32/34 kDa bands were IGFBP-3 (with its classical doublet band of presentation) and IGFBP-2 respectively. Moreover, the ECL method (right half of Fig. 2 ), carried out to increase the sensitivity of our system, showed positive signals only for IGFBPs- 4 and -5 which represent, respectively, the two bands of $29 / 30$ and

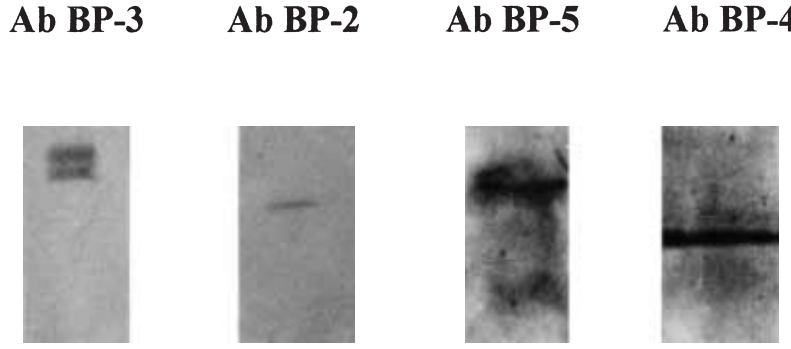

Figure 2 Western immunoblots of IGFBPs in conditioned medium from HRECs. The immunoreactions with AbBP-3 (diluted 1:1000) and AbBP-2 (1:300) were detected by an alkaline phosphatase method; for AbBP-5 (1:300) and AbBP-4 (1:1000) a chemiluminescence peroxidase substrate was used.

$24 \mathrm{kDa}$. In contrast, no positive signals with the two detection methods were found with either IGFBP-1 or IGFBP-6 antisera, even at very high concentration (data not shown). The $18 / 21 \mathrm{kDa}$ band was not correlated with any of the tested antisera.

To determine whether the ability of HRECs to release IGFBPs in conditioned medium reflected a modification of the level of expression of specific IGFBP mRNAs, we performed northern blot analysis of total cellular RNA isolated from HRECs after $48 \mathrm{~h}$ of culture in serum-free conditions. As shown in Fig. 3, of the cDNA probes for human IGFBPs- 1 to -6 tested, only those for IGFBPs- 2 to -5 hybridised (to 2.5-, 2·6-, 2.2-, and 6-kilobase mRNA species respectively). Also in this experiment, confirming the previous observation at the ligand blot analysis, we could not find positive signals for either IGFBP-1 or IGFBP-6 mRNAs. Thus the absence of these two IGFBPs in the ligand blot study may reflect a lack of expression of the respective genes. In contrast, the presence of all the other IGFBP released by HREC was supported by the presence of specific mRNAs that controlled the concentrations of proteins in the HREC conditioned medium.

\section{IGFBP-}

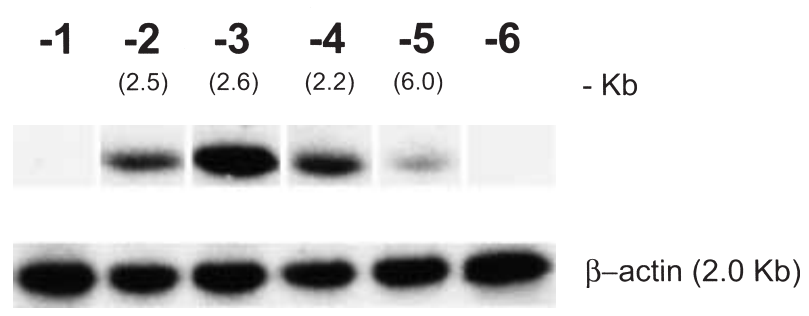

Figure 3 Autoradiogram of northern blots showing expression of IGFBPs in HRECs grown for $48 \mathrm{~h}$ in serum-free conditions. The autoradiograms were obtained after hybridisation with the respective $\left[{ }^{32} \mathrm{P}\right]$-labelled human IGFBP cDNAs. Hybridisation of each total RNA with $\beta$-actin was performed as a control, to estimate the amount of RNA loaded in the various lanes. 


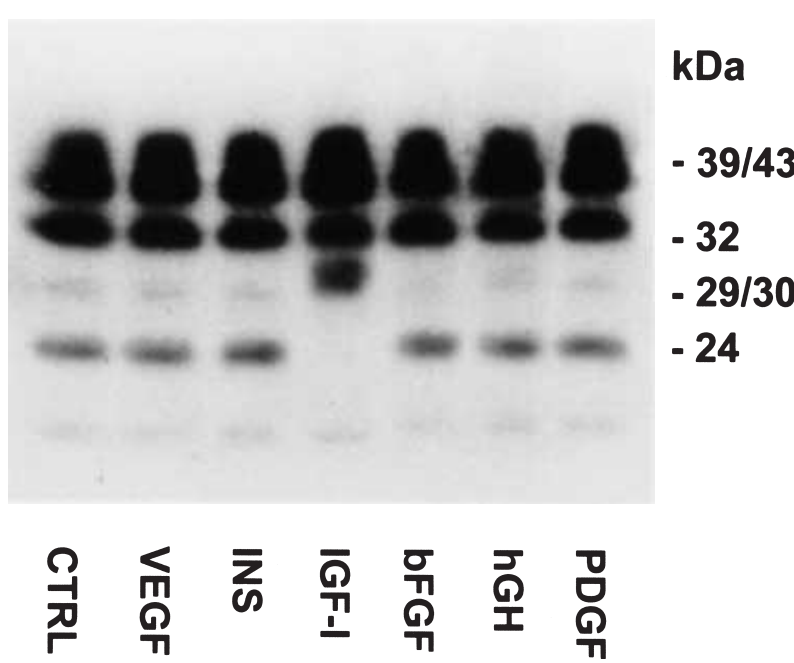

Figure 4 Differential regulation of the four forms of IGFBPs secreted by HRECs. Conditioned media were exposed to $1 \mathrm{nM}$ $\mathrm{GH}$ and $10 \mathrm{nM}$ VEGF, insulin, IGF-I, bFGF and PDGF and then electrophoresed through $10 \%$ SDS polyacrylamide gels, transferred to nitrocellulose filters and probed with [ ${ }^{125}$ I]IGF-II. Known molecular mass standards were run in a parallel lane, as shown on the right. A representative gel is presented. The intensity of the bands was obtained after 3 days of exposure of the autoradiogram.

\section{Regulation of IGFBPs and stimulation of $\left.\beta^{3} \mathrm{H}\right]$ thymidine incorporation into DNA in HRECs}

The effects of several endothelial cell growth factors on the content of IGFBPs in the HREC conditioned medium were investigated. These cells were maintained in a serum-free medium in the presence of $1 \mathrm{nM} \mathrm{GH}$, and 10 nM VEGF, insulin, IGF-I, bFGF and PDGF. After 2 days the conditioned medium were harvested and analysed using $\left[{ }^{125}\right.$ I]IGF-II western ligand blot (Fig. 4). The addition of all the growth factors tested, with the exception of the IGF-I, produced no variation in IGFBP concentration. This lack of effect was confirmed with concentrations of up to $100 \mathrm{nM}$ (data not shown). In contrast, in the presence of $10 \mathrm{nM}$ IGF-I there was complete disappearance of the $24 \mathrm{kDa}$ band (IGFBP-4), accompanied by an accumulation of a $31 \mathrm{kDa}$ band having a doublet profile. Moreover, the weak band of about $18 / 21 \mathrm{kDa}$, observed at the bottom of the autoradiogram and probably representing the IGFBP proteolitic fragments, was not modified in its intensity during the addition of IGF-I or the other growth factors. In order better to characterise the true identity of the $31 \mathrm{kDa}$ band, IGF-I treated HREC conditioned medium was studied by SDS-PAGE electrophoresis followed by $\left[{ }^{125} \mathrm{I}\right] \mathrm{IGF}-\mathrm{II}$ ligand and immunoblotting with AbBP-5 antiserum (Fig. 5). The positive bands obtained with the antibody confirmed the identity of the $31 \mathrm{kDa}$ band as IGFBP-5, even after treatment of the HRECs with IGF-I.

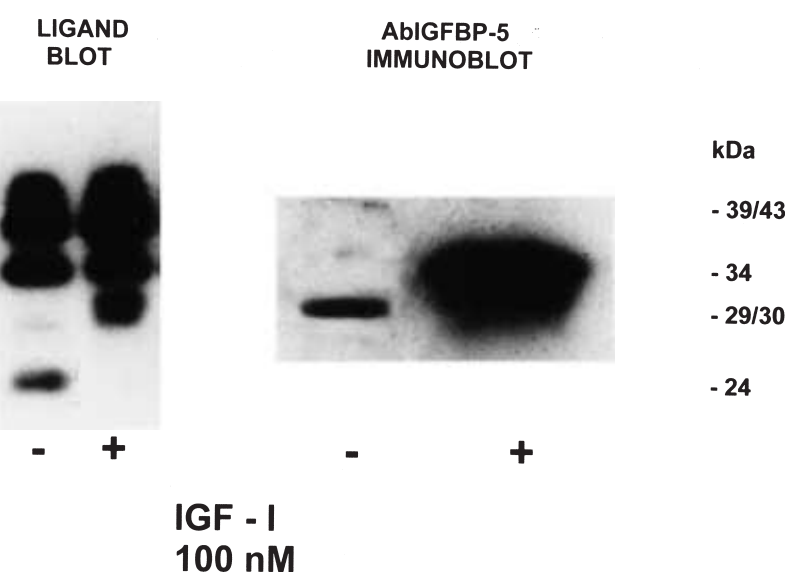

Figure 5 Left: HREC $\left[{ }^{125}\right.$ I]IGF-II ligand blot (autoradiogram obtained after 1 day of exposure). Right: Western immunoblot comparisons in the absence (-) or presence (+) of 100 nM IGF-I. IGFBP-5 in the conditioned medium was identified in the immunoblot study using the AbBP-5 polyclonal antibody (AbIGFBP-5). The positions of molecular mass markers are indicated on the right. An ECL detection system was used to identify the positive immunobands.

In addition to this, the physiological significance of the action of IGF-I on HREC IGFBPs was also evaluated. For this purpose, subconfluent cell layers were exposed to increasing concentrations of IGF-I and the effects both on HREC thymidine incorporation and on the IGFBPs secreted into the conditioned medium were compared (Fig. 6). The lower part of Fig. 6 shows the $\left[{ }^{3} \mathrm{H}\right]$ thymidine incorporation into HRECs as a dose-response histogram. IGF-I in the smallest dose of $0.01 \mathrm{nM}$ significantly $(P<0 \cdot 05)$ stimulated the DNA synthesis and this effect showed a sharp increase (twofold that of control), starting at $0 \cdot 1 \mathrm{nM}(P<0 \cdot 01)$. This statistically highly significant result was maintained up to the highest experimental concentration used $(10 \mathrm{nM})$. The upper part of Fig. 6 shows a ligand blot analysis of the dose-response effect of IGF-I on HREC IGFBPs. IGF-I increased the amount of IGFBP-5 in HREC conditioned medium in a dosedependent manner, starting its effect at $1 \mathrm{nM}$ and with a further increase at the highest dose $(10 \mathrm{nM})$. Conversely, IGF-I produced a progressive decrease in IGFBP-4, starting at $0.01 \mathrm{nM}$, until complete disappearance of this IGFBP band with the highest concentration of IGF-I $(10 \mathrm{nM})$. The densitometric quantification and the statistical analysis of the control of HREC IGFBPs by IGF-I are presented in Fig. 7, together with the densitometric quantification of IGFBPs-4 and -5 expressed as ratio. We observed that, starting from a concentration of $0 \cdot 1 \mathrm{nM}$, IGF-I caused an inversion of this ratio that was maintained for all the experimental doses used. That same dose of IGF-I $(0 \cdot 1 \mathrm{nM})$ produced the sharpest increase in DNA synthesis observed in HRECs. 


\section{I $^{125}$ I|IGF-II Western Ligand Blot}

IGFBP-4

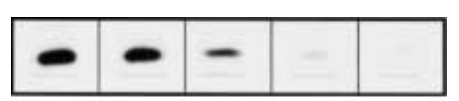

IGFBP-5
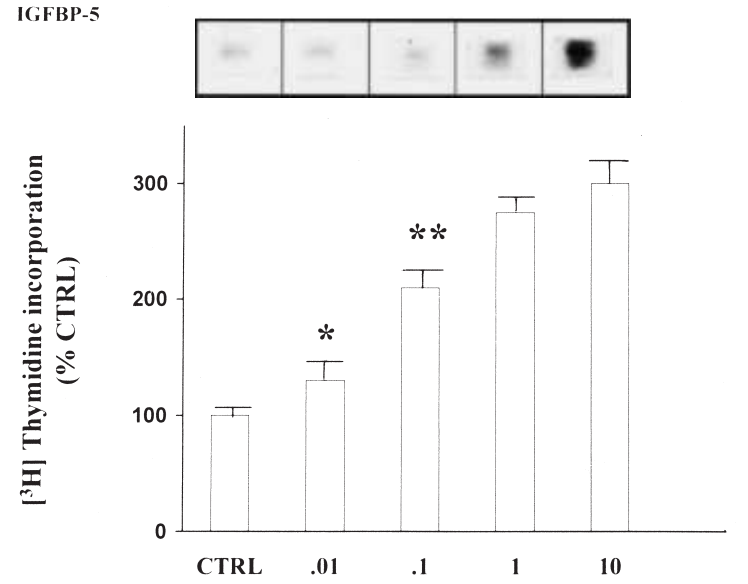

IGF-I nM

Figure 6 IGF-I dose-response experiments in HRECs (doses of IGF-I are shown at the bottom of the figure). The upper parts show isolated bands of IGFBPs- 4 and -5 from a representative single autoradiogram after [ ${ }^{125}$ I]IGF-II western ligand blot analysis. Lower part: Effect of IGF-I on $\left[{ }^{3} \mathrm{H}\right]$ thymidine incorporation (results expressed as percent of control (CTRL)). Data are the means \pm S.D. of six experiments. From $0.01 \mathrm{nM}$ to $10 \mathrm{nM}$ IGF-I, the increase in thymidine incorporation compared with control was constantly significant $\left({ }^{*} P<0 \cdot 05,{ }^{* *} P<0 \cdot 01\right)$.

\section{HREC IGFBPs-4 and -5 and their regulation}

To evaluate the level of the regulation of IGFBPs-4 and -5 by IGF-I, northern blot analysis was carried out (Fig. 8). Northern blots were prepared from HRECs treated for $24 \mathrm{~h}$ in serum-free media alone (lane $\mathrm{C}$, control) or with the addition of $100 \mathrm{nM}$ IGF-I (lane T, treated). There was no change in the $6 \mathrm{~kb}$ IGFBP-5 transcript; conversely, the level of the $2 \cdot 2 \mathrm{~kb}$ transcript for IGFBP-4 was dramatically decreased in the presence of IGF-I. We next determined a possible mechanism for the IGF-I regulation of IGFBP-5 release. Results of a ligand blot study of HREC conditioned medium obtained after $24 \mathrm{~h}$ of addition of several stimuli are shown in Fig. 9A. In a concentration of $5 \mathrm{nM}$, des(1-3)IGF-I, an IGF-I analogue with low affinity for IGFBPs, had no effect on the control profile of IGFBP-5. The same result was seen when a protease inhibitor such as EDTA was added in a concentration of $10 \mathrm{nM}$. In contrast, opposite results were obtained in the co-presence of equimolar concentrations $(10 \mathrm{nM})$ of IGF-I and $\alpha$ IR3, a monoclonal antibody against the IGF-I receptor. Furthermore, to investigate whether IGF-I influenced the

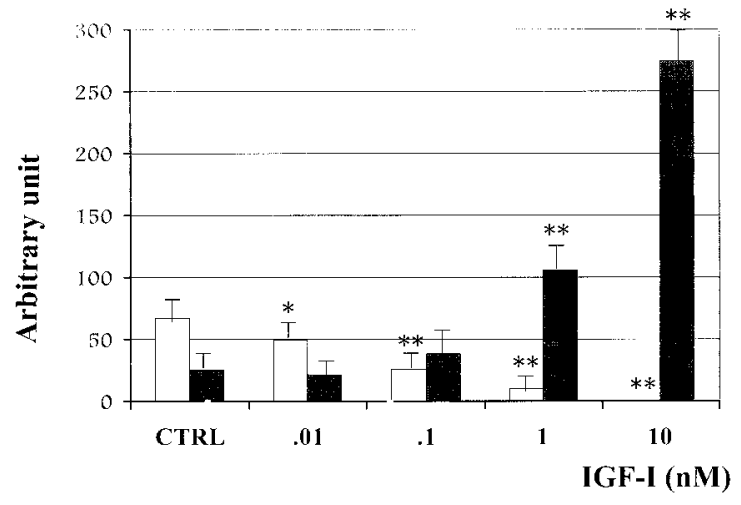

\begin{tabular}{|llllll|}
\hline BP-4/BP-5 & 2.68 & 2.30 & 0.68 & 0.09 & 0.003 \\
\hline
\end{tabular}

Figure 7 Representation of the densitometric evaluation of the dose-response effect of IGF-I on HREC IGFBP-4 ( $\square$ ) and IGFBP-5 ( $\boldsymbol{\square})$. Values are expressed as arbitrary units. The lower part of the figure shows the densitometric quantification of IGFBPs-4 and -5 expressed as ratios (BP-4/BP-5). CTRL, control. ${ }^{*} P<0 \cdot 05,{ }^{*} P<0 \cdot 01$ compared with control.

stability of IGFBPs directly or indirectly, we also incubated HREC-free conditioned medium for $24 \mathrm{~h}$ at $37^{\circ} \mathrm{C}$ alone or with $10 \mathrm{nM}$ IGF-I. No variation in HREC IGFBPs was seen on ligand blot analysis (Fig. 9B).

\section{IGFBP-5 and HREC growth}

We carried out an experiment with the polyclonal IGFBP-5 antibody to determine whether IGFBP-5 could

\section{IGFBP-5}

IGFBP-4

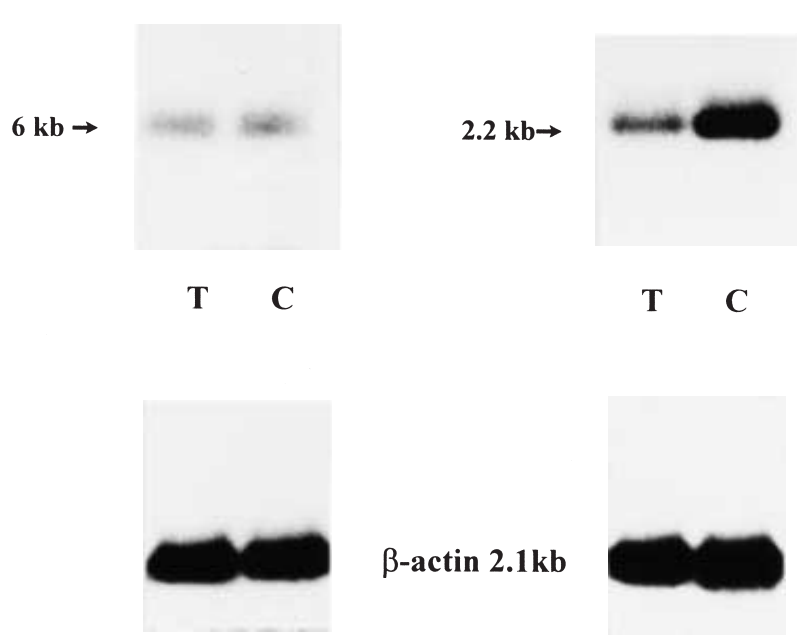

Figure 8 Northern blot analysis of total RNA from HRECs treated (T) with $100 \mathrm{nM}$ IGF-I, compared with the same cells without treatment $(\mathrm{C})$. The arrows denote the position of the approximately $6 \mathrm{~kb}$ IGFBP-5 and $2 \cdot 2 \mathrm{~kb}$ IGFBP-4 mRNAs. 


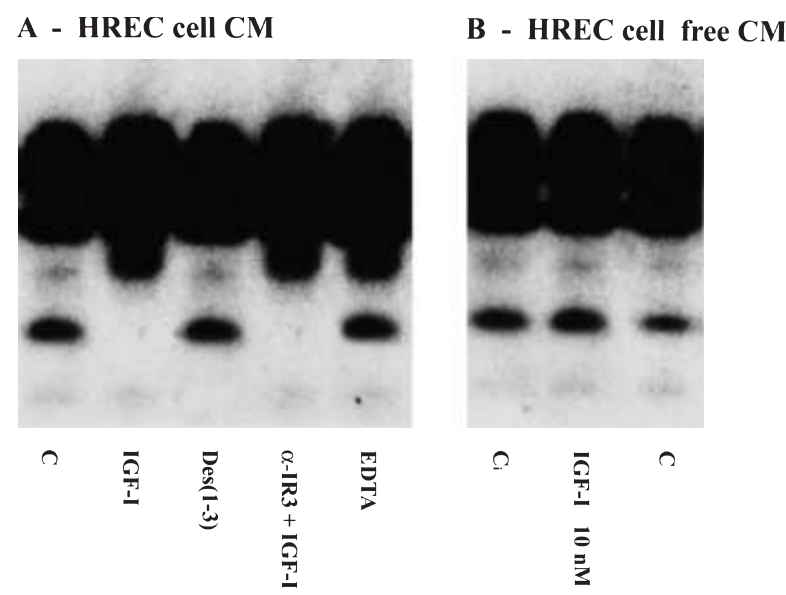

Figure 9 (A) Ligand blot analysis of HREC conditioned medium (CM) obtained after $24 \mathrm{~h}$ of stimulation with $10 \mathrm{nM}$ IGF-I, $5 \mathrm{nM}$ des(1-3)IGF-I, IGF-I $10 \mathrm{nM}+$ equimolar concentration of $\alpha$-IR3 or $10 \mathrm{nM}$ EDTA. (B) Ligand blot analysis of HREC-free conditioned medium incubated for $24 \mathrm{~h}$ at $37^{\circ} \mathrm{C}$ alone or in presence of $10 \mathrm{nM}$ IGF-I. $\mathrm{C}_{\mathrm{i}}$ and $\mathrm{C}$ are control lanes with and without incubation respectively. Representative gels were obtained after a 3-day exposure of the gel.

have a major role in the control of the growth of HRECs (Fig. 10). These cells grown for $48 \mathrm{~h}$ in regular culture medium exhibited an increase $(P<0 \cdot 01)$ in $\left[{ }^{3} \mathrm{H}\right]$ thymidine incorporation $1 \cdot 8$-fold more than that after $24 \mathrm{~h}$ of cell growth. After $24 \mathrm{~h}$ of regular growth, treatment of the HRECs with AbBP-5 (1:100) produced an approximately $1 \cdot 33$-fold reduction $(P<0 \cdot 01)$ in $\left[{ }^{3} \mathrm{H}\right]$ thymidine incorporation of about. To evaluate whether the presence of IGFBP-5 alone could control the growth of HRECs, the cells were treated with different concentrations of rhIGFBP-5. The results presented in Fig. 11 show that up to $1 \mathrm{nM}$ rhIGFBP-5 was able to stimulate HREC

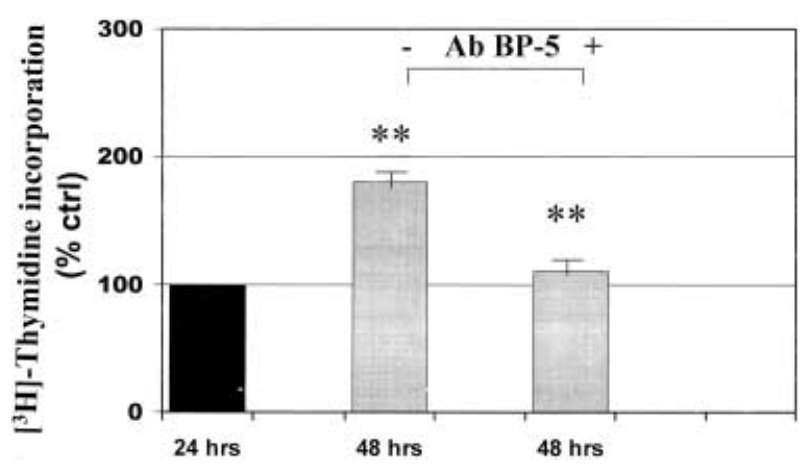

Figure 10 Effect of IGFBP-5 antibody on the growth of HRECs. Cells were cultured in regular medium for $24 \mathrm{~h}$ and then studied for a further $24 \mathrm{~h}$ in the absence $(-)$ or presence $(+)$ of AbBP-5 (1:100). Data represent means \pm S.D. Similar results were obtained in two other independent experiments. ctrl. control. ${ }^{* *} P<0 \cdot 01$.

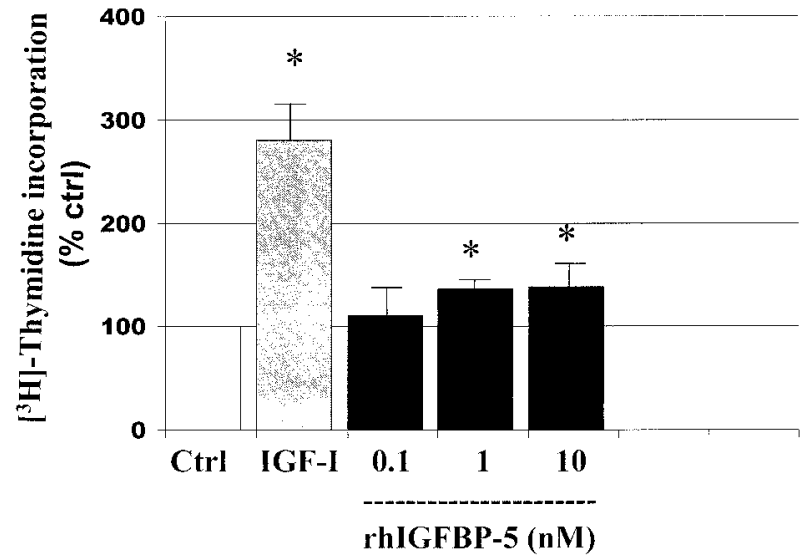

Figure 11 Modulatory effect of rhIGFBP-5 on the proliferation of HRECs. HRECs were plated at subconfluence and maintained for $48 \mathrm{~h}$ in serum-free medium and were then incubated for $24 \mathrm{~h}$ with $1 \mathrm{nM}$ IGF-I or increasing concentrations of rhIGFBP-5 $(0 \cdot 1-10 \mathrm{nM})$. This experiment was performed three times, with similar results. Values reported are means \pm S.D. ${ }^{*} P<0 \cdot 01$ compared with control (ctrl).

growth significantly $(P<0 \cdot 05)$, although to a lesser extent $(2 \cdot 1$-fold) than the effect achieved with 1 nM IGF-I.

\section{HRECs and glucose}

Figure 12 depicts $\left[{ }^{3} \mathrm{H}\right]$ thymidine incorporation by HRECs cultured in normal-glucose $(5 \mathrm{mM})$ and in highglucose $(22 \mathrm{mM})$ media after 7, 14 and 21 days of culture. A slight, but not significant, difference was noted between the two populations of cells after 1 week of culture, compared with regular growth, but the reduction in cell proliferation in high-glucose medium began to attain statistical significance $(P<0 \cdot 05)$ after 2 weeks of culture, maintaining this difference up to 3 weeks of cell growth. This inhibitory effect was not mimicked by equimolar

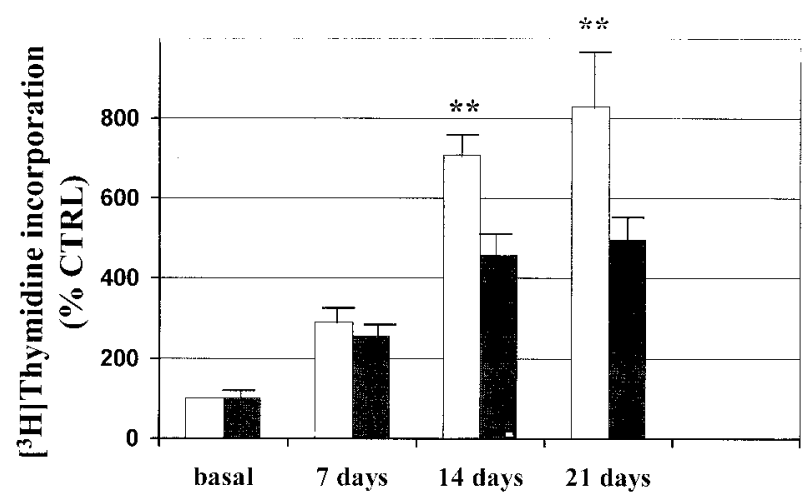

Figure $12\left[{ }^{3} \mathrm{H}\right]$ Thymidine incorporation into HRECs cultured for 3 weeks in $5 \mathrm{mM}(\square)$ glucose medium and with an increased glucose concentration $(22 \mathrm{mM}, \mathbf{\square})$. The results are expressed as percent of control (CTRL). Data represent means \pm S.D. ${ }^{*} P<0 \cdot 05$ compared with $22 \mathrm{mM}$ glucose. 


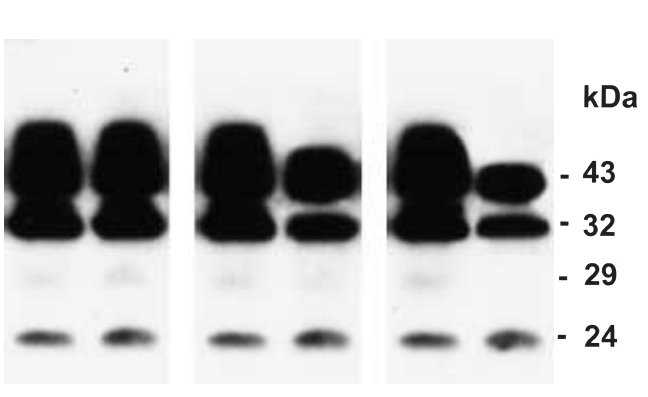

$\begin{array}{lllllll}5 & 22 & 5 & 22 & 5 & 22 & \begin{array}{l}\text { mM glucose } \\ \text { days in culture }\end{array}\end{array}$

Figure 13 [ ${ }^{125}$ I]IGF-II western ligand blot comparisons of IGFBP profiles of HRECs cultured in normal $(5 \mathrm{mM})$ and high $(22 \mathrm{mM})$ concentrations of glucose, after 7, 14 and 21 days. Densitometric quantification showed that the production of IGFBP was unchanged after 7 days of culture, but that, after 14 days, the amounts of IGFBPs-3 and -5 were significantly decreased $(P<0 \cdot 05)$; the concentration of IGFBP-2 was also apparently reduced, but this did not reach statistical significance. At 21 days, the concentrations of IGFBPs-2, -3 and -5 were significantly reduced $(P<0 \cdot 01)$. IGFBP-4 was unmodified at all times of harvesting. A representative autoradiogram after 3 days of exposure of the gel is shown.

concentration of mannitol (data not shown). The effect of chronic high-glucose culture conditions in terms of IGFBP production by HRECs was also studied. Figure 13 presents the ligand blot analysis of $48 \mathrm{~h}$ conditioned medium of HRECs grown in 5 and $22 \mathrm{mM}$ glucose for 7 , 14 and 21 days. Exposure to high glucose produced, with the exception of IGFBP-4, a progressive decrease in concentrations of all the HREC IGFBPs (BP-2, -3 and $-5)$, whereas the IGFBP profiles of HRECs grown in normal glucose or iso-osmolar mannitol (data not shown) were not significantly modified. Densitometric quantification of the IGFBP bands shown in Fig. 13 is shown in Table 1. Statistical analysis revealed that, at 14 days of culture, only IGFBPs-3 and -5 exhibited a significant decrease in their intensity, whereas the reduction in IGFBP-2 was not significant. At 21 days of culture,

Table 1 Densitometric quantification of the western ligand blots of the HREC IGFBP bands in normal $(5 \mathrm{mM})$ and high $(22 \mathrm{mM})$ concentrations of glucose shown in Fig. 13. Data are means \pm S.D. from triplicate determinations

\begin{tabular}{|c|c|c|}
\hline & \multicolumn{2}{|c|}{ Number of cells $\left(\times 10^{5}\right)$} \\
\hline & $5 \mathrm{mM}$ glucose & $22 \mathrm{mM}$ glucose \\
\hline Basal & $0 \cdot 35 \pm 0 \cdot 02$ & $0 \cdot 36 \pm 0 \cdot 08$ \\
\hline 7 days & $4 \cdot 19 \pm 0 \cdot 8$ & $3 \cdot 71 \pm 0 \cdot 1$ \\
\hline 14 days & $10 \cdot 23 \pm 1 \cdot 1$ & $6 \cdot 6 \pm 0.75^{* *}$ \\
\hline 21 days & $12 \pm 2 \cdot 3$ & $7 \cdot 2 \pm 1 \cdot 4^{* *}$ \\
\hline
\end{tabular}

${ }^{* * P}<0 \cdot 01$, compared with $5 \mathrm{mM}$ glucose.
7 days

21 days

IGFBP-3
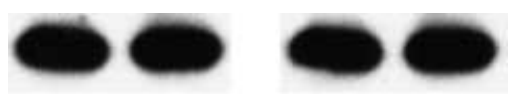

$-2.6 \mathrm{~Kb}$

IGFBP-2
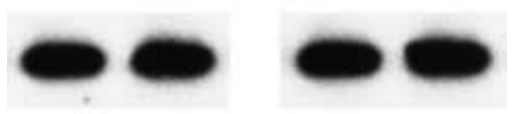

$-2.5 \mathrm{Kh}$
IGFBP-5

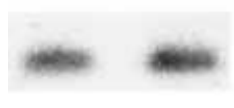

$\beta-A C T I N$

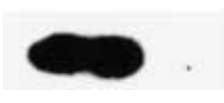

N $\mathbf{H}$
$-6.0 \mathrm{~Kb}$

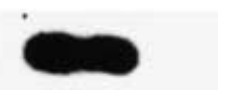

$-2.0 \mathrm{Kh}$

\section{N $\mathbf{H}$}

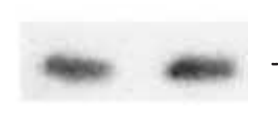

Figure 14 Northern blot analysis of the expression of IGFBPs-2, -3 and -5 and $\beta$-actin gene in HRECs cultured in $5 \mathrm{mM}(\mathrm{N})$ or $22 \mathrm{mM}(\mathrm{H})$ glucose for 21 days (autoradiograms representative of three experiments). Statistical analysis of IGFBP bands (after densitometric quantification followed by normalisation to the $\beta$-actin bands) showed no significant change between 7 and 21 days of culture.

however, all the IGFBPs involved in high-glucose regulation showed a highly significant reduction in their profile. We next compared the expression of mRNA of the IGFBPs involved in high-glucose regulation after 7 and 21 days of culture. The data shown in Fig. 14 demonstrate that a high glucose concentration did not affect the expression of IGFBPs-2, -3 and -5 mRNAs. Iso-osmolar mannitol treatment, similarly, failed to modify the IGFBP mRNA levels (data not shown).

\section{Discussion}

One cause of proliferative diabetic retinopathy, in addition to the altered glycaemic control, is probably an exaggerated response of the IGF system to a local injury. As remarked by Merimee (1997), the IGF-I, directly or indirectly through the modulation of IGFBPs, seems to have an important role in this microangiopathy. The present study has demonstrated that HRECs express and release four different types of IGFBPs and, for the first time, has shown that IGF-I is able to modify the presence of these IGFBPs. We also found that chronic (3 weeks) exposure of HRECs to $22 \mathrm{mM}$ of glucose affects the 
concentrations of the IGFBPs and, consequently, endothelial growth.

Among all the endothelial growth factors tested in HRECs, only IGF-I was able to modulate the IGFBP secretory pattern in a dose-response manner. The data we obtained for characterisation of IGFBPs confirmed the secretory pattern of HRECs previously reported (Spoerni et al. 1998). In general, endothelial cells cultured from different sources, have been reported to express and release into their conditioned medium a quite similar profile of IGFBPs (-2 to -6$)$, with a particularly constant presence of IGFBP-4 (Bar et al. 1989, Moser et al. 1992, Yang et al. 1993, Moriarty et al. 1994, Spoerni et al. 1998).

We observed that IGF-I produced a dramatic decrease in IGFBP-4 and that this control was exerted at the transcriptional level, confirming our previous study in human endothelial cells (Giannini et al. 1999). As an IGF-I-dependent proteolitic mechanism for the regulation of IGFBP-4 has been demonstrated (Myers et al. 1993), modification of the expression of IGFBP-4 mRNA rules out the possibility that this enzymatic mechanism could be located largely in endothelial cell conditioned medium. Moreover, we found that IGF-I is also able to regulate IGFPB-5 and to produce an increase in IGFBP5 molecular mass from $29 \mathrm{kDa}$ to the IGF binding triplet of $29 / 32 / 34 \mathrm{kDa}$, as has been observed in other cell lines (Conover \& Kiefer 1993) and identified as the O-glycosylated form of the solitary $29 \mathrm{kDa}$ IGFBP-5. Confirming our results obtained in bovine endothelium (Giannini et al. 1997), in HRECs IGF-I at maximal concentration produced an approximately 100-fold increase in conditioned medium IGFBP-5, but had no effect on steady-state levels of IGFBP-5 mRNA, suggesting that the availability of IGFBP-5 is determined in large part at a post-transcriptional level. In human fibroblasts (Camacho-Hubner et al. 1992), exposure to IGF-I produced an increase in intact IGFBP-5 through inhibition of a specific proteolytic serine protease the activity of which is inhibited by $\alpha_{1}$-anti-chymotrypsin and EDTA (Clemmons 1995). This enzyme is able to produce IGFBP-5 fragments of about $23 \mathrm{kDa}$, detectable by immunoblot analysis (Arai et al. 1994). In our study, an IGFBP fragment band of $18-21 \mathrm{kDa}$ could be detected in basal conditions, suggesting that some degradation had occurred. However, the immunoblot study we performed with commercial IGFBP-5 polyclonal antibody did not reveal this fragment band. Furthermore, we observed that there was no modification of this $18-21 \mathrm{kDa}$ band in the presence of IGF-I and with EDTA. All these data suggest that, as in other endothelial cells, no IGFBP-5 proteolitic activity (or little, if any) was present in HREC conditioned medium. Therefore, the lack of modification of the levels of IGFBP-5 mRNA, together with the protection afforded by IGF-I against proteolysis, may not represent the entire mechanism, and a possible direct effect of IGF-I on IGFBP-5 needs to be considered also. In fact, in this study we showed that not only was the use of the specific IGF-I receptor inhibitor, $\alpha$ IR3 antibody, unable to block the increase in concentrations of IGFBP-5 in the presence of IGF-I, but also, in accordance with the findings of a previous study in osteoblastic cells (Conover \& Kiefer 1993), an interaction between IGF-I and IGFBP-5 appears to be necessary to increase the concentrations of this binding protein in HREC conditioned medium. In fact, both insulin and the IGF-I analogue, des(1-3)IGF-I, with low affinity for the IGFBPs, were unable to modify the IGFBP-5 band. Specific binding sites for IGFBP-5 have yet to be identified, but the characterisation of its binding to endothelial cells has revealed that glycosaminoglycan can compete for IGFBP-5 at the cell surface (Booth et al. 1995); in addition, IGFBP-5 can bind to extracellular matrix components (EMCs) derived from endothelial cells (Jones et al. 1993). Thus, although further studies could clarify the role attributed to IGF-I in IGFBP-5 regulation, the experimental model that we used in HRECs could suggest the hypothesis that a possible increase in IGFBP-5 concentrations occurs after detachment of this binding protein from the cell membrane or EMC depots that is induced by IGF-I through an IGF-I receptor-independent mechanism (Giannini et al. 1997), confirming our previous observations in endothelial cells. In fact, during $24 \mathrm{~h}$ cell-free incubation of HREC conditioned medium in the presence of IGF-I, this peptide was unable to increase the concentration of the IGFBP-5 band, suggesting that the presence of both HRECs and EMCs is necessary to modify the IGFBP-5 band. Because the amount of IGFBP-5 bound to EMCs in endothelial cells is modest (Arai et al. 1994), the main source of this binding protein could be represented by the cell membrane surfaces.

In a previous report (Giannini et al. 1999) we hypothesised a common mechanism for IGF-I in regulating the growth of all the different types of endothelial cell, which was essentially dependent on the control of IGFBPs-3 and -4. Although IGFBP-3 was not modulated by IGF-I in HRECs, in contrast to the findings in other endothelial cells types we have previously studied (Giannini et al. 1997, 1999), this lack of regulation was not relevant to an explanation of the control of growth of HRECs. In fact, we demonstrated that the presence of IGFBP-3 in human endothelial cells is, per se, a factor making the endothelial cells sensitive to the mitogenic stimulus of IGF-I (Giannini et al. 1999). With respect to IGFBP-4, the downregulation described is particularly relevant, as a constant inhibitory effect of this IGFBP on the actions of IGF on different types of endothelial cells has been demonstrated (Boes et al. 1992, Yang et al. 1993, Giannini et al. 1997, 1999). However, the fact that HRECs release into their conditioned medium detectable concentrations of IGFBP-5, which are modulated by IGF-I, could suggest the concept that this binding protein also may have a role in the proliferation of HRECs. No data are available 
concerning the action of IGFBP-5 in regulating endothelial cell growth. In other experimental models this IGFBP has been demonstrated to inhibit or to potentiate the actions of IGF-I, probably as a result of its ability to associate with the cell membrane surface and components of the extracellular matrix (Rajaram et al. 1997). Several molecular mechanisms by which IGFBP-5 stimulates IGF-I-induced cell proliferation have been proposed. On the basis of our experimental data, in which an antibody against IGFBP-5 was able to block the regular growth of HRECs, and of the observation that the presence of rhIGFBP-5 alone was able to induce growth of HRECs, it could be assumed that a large amount of intact free IGFBP-5 is necessary in the conditioned medium of HRECs to control HREC mitogenesis, creating, as already observed (Ewton et al. 1998), a favourable ratio between IGFBP-5 and IGF-I. Thus we could assume that HREC growth could depend on the determinant presence of IGFBP-3, together with an equilibrium between IGFBP-4 (inhibiting protein) and IGFBP-5 (stimulating protein). In affecting this equilibrium by the addition of rhIGFBP- 5 or by the presence of IGF-I (which decreased IGFBP-4 and increased IGFBP-5), we observed a stimulatory action on the growth of HRECs, as confirmed by the fact that the inversion of the IGFBP-4/IGFBP-5 ratio became statistically significant at the same concentration at which IGF-I was able to stimulate HREC growth significantly.

An important consideration that has to be taken in account is that, in diabetes mellitus, the actions of the IGF system in local tissues may be modified when glucose concentrations are increased (Lee et al. 1989). For this reason, we investigated the effect of chronic concentrations of glucose on HREC IGFBPs and, subsequently, on their growth. This is, to our knowledge, the first report analysing human retinal endothelial cell IGFBPs in response to prolonged exposure to high concentrations of glucose. Confirming our previous findings in on bovine retinal endothelial cells (Giannini et al. 1997), we showed that, after 3 weeks of culture in high concentrations of glucose, HRECs exhibited a decrease in all the IGFBPs except for IGFBP-4, but a different timing of this reduction in IGFBP was observed. In fact, human retinal endothelial IGFBPs-3 and -5 seem to be more sensitive to the effect of high glucose concentrations, because their release was significantly reduced only after 2 weeks of culture. A previous report (Spoerni et al. 1998) quantified the different pattern of IGFBPs obtained in HRECs from diabetic and non-diabetic patients. The different results were probably a reflection of the fact that, in our study, the investigation of normal HRECs exposed to chronic highglucose culture was an attempt to direct attention to the early modification of endothelial IGFBPs. We showed that chronic exposure to high glucose determined this reduction in IGFBP profile, as has also been reported in different experimental cell models such as rat and human mesangial cells (Pugliese et al. 1996), suggesting that a general common toxic effect could be the convergent mechanism in the control of IGFBP concentrations in different cell systems through chronic exposure to high concentrations of glucose. In HRECs, the mechanism underlying this effect was not related either to the modification of the mRNA levels or, as already reported in bovine retinal endothelium (Giannini et al. 1997), to osmotic damage, because equimolar concentration of mannitol did not impair the production of IGFBP. However, if we examine more closely the types of HREC IGFBPs involved in chronic high-glucose control, we observe that IGFBPs- $2,-3$, and -5 present sites of association on the matrix/cell surfaces (Bach \& Rechler 1992). In contrast, IGFBP-4, the only IGFBP not regulated by glucose, has no matrix/cell binding sites (Bach \& Rechler 1992). Thus it might be hypothesised that one of the mechanisms through which glucose exerts its effect on HREC IGFBPs could be a biochemical modification of the protein matrix/cell surface or of the components involving the IGFBP heparin-binding sequence.

The significance of this reduction in IGFBP that is induced in the presence of high concentrations of glucosebecomes clear when we analyse the growth curve of HRECs chronically cultured in high-glucose conditions. In vitro data consolidated the concept of a deterioration in the growth of endothelial cells exposed to high concentrations of glucose (Lorenzi et al. 1985). The growth of HRECs in high-glucose conditions has been extensively studied by Rymaszewski et al. (1992), who showed that the proliferation of HRECs after 9 days of culture in high-glucose medium was reduced. The present findings in HRECs are generally in agreement with the findings of that earlier study, showing a reduction in cell growth, although the time of appearance of this effect was delayed. In our study a significant decrease in cell numbers was observed after only 2 weeks of culture, becoming more consistent after 3 weeks. This difference could find explanation in both the disparate culture media used and the different cell culture passages utilised. For growth studies, we used endothelial cells between the 3rd and the 5th passages, whereas Rymaszewski's group used cells after the 5th passage. Among the mechanisms whereby increased glucose concentrations reduce the proliferation of endothelial cells, some role for hypertonicity has been suggested (Lorenzi et al. 1985). Experiments in HRECs performed with equimolar concentration of mannitol did not modify the growth of these cells, thus excluding this hypothesis. Instead, on the basis of our findings, if we direct our attention to the modification of the IGFBP profile during the growth of HRECs in high-glucose medium, we observed that the significant reduction in HREC growth was present after 2 weeks of culture, at which time a parallel significant decrease in both IGFBP-3 and IGFBP-5 was also found. Thus, consistent with the findings concerning IGF-I-induced growth of HRECs, in 
which the inhibitory IGBFP-4 was reduced and a parallel increase in IGFBP-3 and the stimulatory IGFBP-5 was observed, the IGFBPs also have an important role in the glucose-reduced proliferation in these cells. This effect was essentially developed by decreasing both IGFBPs-3 and -5 and, conversely, leaving IGFBP-4 unmodified.

In summary, in the present study, we have demonstrated that HRECs secrete large amounts of IGFBPs (IGFBPs-2 to -5 ) and have shown for the first time that they specifically modulate the IGF-I-induced growth in these cells. This effect was, essentially, the result both of a reduction of the inhibitory IGFBP-4 and of an increase in the stimulatory IGFBP-5. High concentrations of glucose participate in reducing the growth of HRECs, with a general decrease in IGFBPs without the involvement of the inhibitory IGFBP-4. Even within the limits of the in vitro model, these findings pinpoint the local IGF system as one of the candidates for a role in human proliferative diabetic retinopathy. Thus we can assume that an early rearrangement of the endothelial IGFBP profile as a result of chronically increased glucose concentrations could produce a greater susceptibility of retinal endothelial cells to the effect of free local IGF-I of autocrine or paracrine origin, which may represent one of the conditions responsible for an exaggerated proliferation of endothelial cells.

\section{Acknowledgements}

This study was supported by grants to C M Rotella from the Italian Ministry for University and Scientific and Technological Research (MURST 60\%, Rome, Italy).

\section{References}

Arai T, Arai A, Busby WH \& Clemmons DR 1994 Glycosaminoglycans inhibit degradation of insulin-like growth factor binding protein-5. Endocrinology 135 2358-2363.

Bach LA \& Rechler MM 1992 Insulin-like growth factors and diabetes. Diabetes and Metabolism Review 3 228-257.

Bar RS, Booth BA, Boes M \& Dake BL 1989 Insulin-like growth factor-binding proteins from vascular endothelial cells: purification, characterisation and intrinsic biological activities. Endocrinology 125 1910-1920.

Boes M, Booth BA, Sandra A, Dake BL, Bergold A \& Bar RS 1992 Insulin-like growth factor binding protein (IGFBP-4) accounts for the connective tissue distribution of endothelial cell IGFBPs perfused through the isolate heart. Endocrinology 131 327-330.

Booth BA, Boes M, Andress DL, Dake BL, Kiefer MC, Maack C, Linhardt RJ, Bar K, Caldwell EE \& Weiler J 1995 IGFBP-3 and IGFBP-5 association with endothelial cells: role of C-terminal heparin binding domain. Growth Regulation 5 1-17.

Camacho-Hubner C, Busby WH, McCusker RH, Wright G \& Clemmons DR 1992 Identification of the forms of insulin-like growth factor binding proteins produced by human fibroblast and the mechanisms that regulate their secretion. Journal of Biological Chemistry 267 11949-11956.

Chomczynsky P \& Sacchi N 1987 Single-step method of RNA isolation by acid guanidium thiocyanate-phenol-chloroform extraction. Analytical Biochemistry 162 156-159.
Clemmons DR 1995 Role of insulin-like growth factor binding proteins in controlling IGF actions. Molecular and Cellular Endocrinology 140 19-24.

Conover CA \& Kiefer MC 1993 Regulation and biological effect of endogenous insulin-like growth factor binding protein-5 in human osteoblastic cells. Journal of Clinical Endocrinology and Metabolism 76 $1153-1159$.

Ewton DZ, Coolican SA, Mohan S, Chrnausek SD \& Florini JR 1998 Modulation of insulin-like growth factor actions in L6A1 myoblasts by insulin-like growth factor binding protein (IGFBP)-4 and IGFBP-5: a dual role for IGFBP-5. Journal of Cellular Physiology 177 $47-57$.

Giannini S, Mohan S, Galli G, Rotella CM, LeBon TR \& FujitaYamaguchi Y 1994 Characterization of insulin-like growth factor binding proteins (IGFBPs) produced by cultured fibroblasts from patients with NIDDM, IDDM and obesity. Journal of Clinical Endocrinology and Metabolism 79 1824-1830.

Giannini S, Cresci B, Manuelli C, Fujita-Yamaguchi Y, Romagnani P, Mohan S \& Rotella CM 1997 Insulin-like growth factor binding proteins production in bovine retinal endothelial cells. Metabolism 46 1367-1379.

Giannini S, Cresci B, Pala L, Ciucci A, Manuelli C, FujitaYamaguchi Y, Cappugi P \& Rotella CM 1999 Human glomerular endothelial cells IGFBPs are regulated by IGF-I and TGF- $\beta 1$. Molecular and Cellular Endocrinology 154 123-136.

Grant MB, Russel B, Fitzgerald C \& Merimee TJ 1986 Insulin-like growth factors in vitreous: studies in controls and diabetic subjects with neovascularization. Diabetes 35 415-420.

Grant MB, Caballero S \& Millard WJ 1993a Inhibition of IGF-I and b-FGF stimulated growth of human retinal endothelial cells by the somatostatin analogue, octreotide: a potential treatment for ocular neovascularization. Regulatory Peptides 48 267-278.

Grant MB, Mames RN, Fitzgerald C, Ellis EA, Aboufriekha M \& Guy J 1993 Insulin-like growth factor-I acts as angiogenetic agent in rabbit cornea and retina: comparative studies with basic fibroblasts growth factor. Diabetologia 36 282-291.

Hossenlop P, Seurin D, Segovia-Quinson B, Hardouin S \& Binoux M 1986 Analysis of serum insulin-like growth factor binding protein using western blotting: use of the method for titration of the binding proteins and competitive binding studies. Analytical Biochemistry 154 138-143.

Jones JI \& Clemmons DR 1995 Insulin-like growth factors and their binding protein: biological actions. Endocrine Reviews 16 3-34.

Jones JI, Gockerman A, Busby Jr WH, Camacho-Hubner C \& Clemmons DR 1993 Extracellular matrix contains insulin-like growth factor binding protein-5: potentiation of the effects of IGF-I. Journal of Cellular Biology 121 679-687.

Kim HS, Nagalla SR, Oh Y, Wilson EM, Roberts CT Jr \& Rosenfeld RG 1997 Identification of a family of low affinity insulin-like growth factor binding proteins (IGFBPs): characterization of connective tissue growth factor (CTGF) as a member of the IGF superfamily. PNAS 94 12981-12989.

King GL, Goodman AD, Buzney S, Moses A \& Kahn CR 1985 Receptors and growth promoting effect of insulin and insulin-like growth factors on cells from bovine retinal capillaries and aorta. Journal of Clinical Investigation 75 1028-1036.

Lee TS, Saltzman KA, Ohashi H \& King GL 1989 Activation of protein kinase $\mathrm{C}$ by elevation of glucose concentration: proposal for a mechanism in the development of diabetic vascular complications. PNAS 86 5141-5145.

Lorenzi M \& Cagliero E 1991 Pathophisiology of endothelial and other vascular cells in diabetes mellitus. Diabetes 40 653-659.

Lorenzi M, Cagliero E \& Toledo S 1985 Glucose toxicity for human endothelial cells in culture. Diabetes 34 621-627.

Lorenzi M, Nordberg JA \& Toledo S 1987 High glucose prolongs cell-cycle traversal of cultured human endothelial cells. Diabetes 36 1261-1267. 
Merimee TJ 1997 The interface between diabetic retinopathy, diabetes management, and insulin-like growth factors [editorial]. Journal of Clinical Endocrinology and Metabolism 82 2806-2808.

Meyer Schwickerath R, Pfeiffer A \& Blum WF 1993 Vitreous levels of the insulin-like growth factor binding proteins 2 and 3 increase in neovascular eye disease. Studies in nondiabetic and diabetic subjects. Journal of Clinical Investigation 92 2620-2626.

Moriarty P, Boulton M, Dickson A \& McLeod D 1994 Production of IGF-I and IGF binding protein by retinal cells in vitro. British Journal of Ophthalmology 78 638-642.

Moser DR, Lowe WL, Dake BL, Booth BA, Boes M, Clemmons DR \& Bar RS 1992 Endothelial cells express insulin-like growth factor-binding proteins 2 to 6. Molecular Endocrinology 6 1805-1814.

Myers SE, Cheung PT, Handwerger S \& Chernausek SD 1993 Insulin-like growth factor-I (IGF-I) enhanced proteolysis of IGFbinding protein- 4 in conditioned medium from primary cultures of human decidua: independence from IGF receptor binding. Endocrinology 133 1525-1531.

Paques M, Massin N \& Gaudric A 1997 Growth factors and diabetic retinopathy. Diabetes and Metabolism 23 125-130.

Pugliese G, Pricci F, Locuratolo N, Romeo G, Galli G, Casini A, Rotella CM, Di Mario U \& Pugliese F 1996 Increased activity of insulin-like growth factor system in mesangial cells cultured in high glucose conditions. Relation to glucose-enhanced extracellular matrix production. Diabetologia 39 775-784.

Rajaram S, Baylink DJ \& Mohan S 1997 Insulin-like growth factor binding proteins in serum and in other biological fluids: regulations and functions. Endocrine Reviews 18 801-831.

Rotella CM, Mavilia C, Frediani U \& Toccafondi R 1989 Calf serum modifies the mitogenic activity of epidermal growth factor in WRT thyroid cells. Molecular and Cellular Endocrinology 65 63-74.
Rudermann NB, Williamson JR \& Brownlee M 1992 Glucose and diabetic vascular disease. FASEB Journal 6 2905-2914.

Rymaszewski Z, Szymanski PT, Abplanalp WA, Myatt L, Di Salvo J \& Cohen RM 1992 Human retinal vascular cells differ from umbilical cells in synthetic functions and their response to glucose. Proceedings of the Society for Experimental Biology and Medicine 111 183-191.

Shimasaki S \& Ling N 1991 Identification and molecular characterization of insulin-like growth factor binding proteins (IGFBP-1, -2, -3, -4, -5, -6). Progress in Growth Factor Research 3 243-266.

Spoerni PE, Ellis EA, Tarnuzzer RW \& Grant MB 1998 Insulin-like growth factor: receptor and binding proteins in human retinal endothelial cell cultures of diabetic and non-diabetic origin. Growth Hormone and IGF Research 8 125-132.

Su T \& Gillies MC 1992 A simple method for in vitro culture of human retinal capillary endothelial cells. Investigative Ophthalmology and Visual Science 33 2809-2813.

Tucci M, Nygard K, Tanwell BV, Faber HW, Hill DJ \& Han VK 1998 Modulation of insulin-like growth factor (IGF) and IGFbinding protein biosynthesis by hypoxia in cultured vascular endothelial cells. Journal of Endocrinology 157 13-24.

Yang YW, Pioli P, Fiorelli G, Brandi ML \& Rechler MM 1993 Cyclic adenosine monophosphate stimulates insulin-like growth factor-binding protein-4 and its messenger ribonucleic acid in a clonal endothelial cell line. Endocrinology 133 343-351.

Received in final form 3 July 2001

Accepted 9 July 2001 